\title{
Possibilities of family medicine in medical education
}

\author{
Igor Švab
}

Department of family medicine University of Ljubljana, Medical faculty Ljubljana, Slovenia

Corresponding author: Igor Švab

University of Ljubljana

Medical faculty

Department of family medicine

Poljanski nasip 58

1000 Ljubljana

Slovenia

igor.svab@mf.uni-lj.si

Tel.: + 386-1-438-69-15

Fax: + 386-1-438-69-10

Received: 20 December 2011

Accepted: 30 March 2012

Copyright (C) 2012 by

Academy of Sciences and Arts

of Bosnia and Herzegovina.

E-mail for permission to publish:

amabih@anubih.ba

\begin{abstract}
Family medicine is a discipline that has only recently joined the academic arena. Because of this, the academic contribution of this discipline to universities has not been clarified yet. On the other hand, the medical schools suffer from well-known challenges, that have been largely known in the discussions about the crisis of academic medicine. The article explores the possibilities of mutual cooperation between family medicine and the universities. In order to profit from the qualities of academic medicine and family medicine, a partnership between the two needs to be established. It should be built on acceptance of differences and adaptation of family medicine to the rules of the academia, which should be done without sacrificing its principles. The author describes three potential scenarios how family medicine can be introduced in the undergraduate curriculum: a) as a subject at the end of the curriculum, b) as collaboration in early patient contact and teaching clinical skills and c) as part of the integrated curriculum.The author concludes that both family medicine and the medical school have a lot to benefit from mutual cooparation. This requires compromises that are not always easy.
\end{abstract}

Key words: Education/graduate, Family medicine, Curriculum.

\section{Introduction}

It is well known that medical schools suffer from challenges, that have been clearly articulated as the crisis of academic medicine $(1,2)$. The universities are being challenged for not being able to respond to the challenges of the modern world (3), that they do not relate to the problems of the modern world and that they are not interesting for the brightest and the best (4).

It has largely been argued that the introduction of family medicine at the medical curricula can help in solving some of these challenges (5). This argument was often a driving force behind the implementation of academic family medicine, which has only recently joined the academic arena. This has been largely recognised as a success of a discipline that has for a long time been denied its academic dimension (6). The process was pronounced in the second half of the twentieth century, when a number of departments of family medicine were established throughout the developed world (7). 
One of the main contributions of family medicine is in the innovative methods of education that family medicine can offer. Among them one-to-one teaching in paractice is the hallmark of family medicine teaching (8-10). Other methods are also introduced: role playing, small group teaching, etc (11).

Family medicine also has a potential of bringing new concepts that are often not recognised or poorly implemented (prevention (12), multimorbidity, community orientation, family, organisation of practice) ( 9 , 12-14). All these subjects are essential for the modernisation of curricula at medical schools (15). The new concepts in medical education should be introduced not only in education, but also in research priorities of an university (16).

But the practicalities of this implementation are often less successful. We now often encounter new departments of family medicine that although they are part of the academic structure, do not contribute to solving of this problem. Sometimes, family medicine has also become a part of the same problem of sterile academic medicine, because the introduction of family medicine was not done in a way that would take advantege of its potential of innovative approaches to the academia (17).

Some of this is due to the fact that the academic contribution of this discipline to universities has not been clarified yet. The aim of this paper is to look at the potential soultions to this issue.

\section{Options for partnership}

In order to improve the situation, a partnership needs to be established that would ensure higher quality of teaching and research. The partnership between the two should be based on acceptance of common problems and charactersitics. The univeristies should accept family medicine as an equal partner and the family medicine should accept the standards that are valid within the medical schools.

Family medicine has a lot to offer to the medical schools (18). Due to the high workload, it has access to a lot of clinical cases that can be useful in teaching basic clinical skills. Because a lot of doctors work in primary care, it is potentially a resource of future teachers. It can also offer a different perspective of the world and a different approach to solving problems in clinical medicine. The problems of family medicine are sometimes related to a lack of academic tradition. Doctors in family medicine are often overworked and often do not see the need to work academically. These limitations need to be taken into consideration when looking at the options how it can be introduced into the curriculum. There are three principal options how family medicine can contribute to the undergraduate curriculum of a medical school.

\section{Option 1: Integration and application}

This is usually the first option when family medicine is being introduced to the medical school. The aim of this approach is to use family medicine as a subject where students can practise their clinical skills before finishing their careers as students. The second aim of this approach is to use the family medicine environment for the integration and implementation of knowledge from previous years during the study. It usually takes a form of a subject at the end of the study, when family medicine is considered a part of a residency, providing the students with much needed application of the clinical knowledge and application in practice. Family medicine is generally seen as a discipline that offers future doctors the much needed oportunity to work independently with patients (19). In fomer Yugoslavia, family medicine was introduced in that way in all 
medical schools when the programmes were extended from five to six years. Not all medical schools have implemented this change, however.

\section{Option 2: Cooperation}

Introducing successfully family medicine at the undergraduate level usually results in a need for collaboration of family medicine with other departments, where family medicine can contribute to topics like the early patient contact and sometimes propedeutics. This usually happens after family medicine has already been introduced and other departments see the potential of family medicine not only in practice and integration at the end of the study, but also in contribution to their subjects (mainly clinical). Family medicine can be helpful in many ways. One of the possibilities is to help in providing a teaching environment for teaching basic clinical skills (propedeutics), which is becoming increasingly difficult to do in a highly specialised hospital environment. Teaching basic clinical skills is increasingly done in primary care, where students can encounter a lot of patients in a relatively short period of time. The other possibility is to add family medicine experience to clinical subjects so that students can learn about common diseases and how they are presented in primary care. Family medicine can also be used successfully during early patient exposure in earlier years of the study (20). This kind of collaboration is a more difficult one, because it requires more negotiations with other disciplines that are usually well established within the medical school.

\section{Option 3: Integration}

The full potential of family medicine is usually expressed in an integrated curriculum where family medicine can contribute to virtually every subject at the undergraduate level (21). With this option, family medicine can contribute to most of the subjects during the curriculum. The curriculum itself is integrated and the classical subjacts (e.g. surgery, internal medicine) are usually replaced by different topics that reflect integration of knowledge (22). This modern approach to curriculum design is getting increasingly recognised as a better option to the traditional one. It, however, takes a certain degree of maturity of the medical school to embrace this approach. However, the introduction of an integrated curriculum is a big challenge for the medical school and is not always easily achievable (23).

\section{Challenges}

This stepwise approach how medical schools can contribute from the implementation of family medicine in its curriculum was experienced by several departments and medical schools. As every change, it is usually combined with a set of difficulties that need to be overcome.

\section{Challenges to the university}

The difficulties origine from both sides. The university needs to adapt its curricula in order to use the potential of family medicine. This means that it often needs to accomodate to a different style of practice based teachers than they were used to. Family medicine has a different paradigm of medicine (24), which is sometimes in conflict with traditional concepts that prevail in most medical schools nowadays.

Classically, family medicine works with practice-based teachers that have a special position in the curiculum and do not fit entirely the standards for teachers that are readily accepted by the medical schools ( 25 , 26). Their position needs to be recognised. They need to be subjected to reaccreditation 
regarding their academic standards, which is different from prevailing reaccreditition for doctors. They need to be properly reimbursed or acknowledged.

\section{Challenges to family medicine}

On the other hand, family medicine has to overcome some of its internal barriers. As a first step, family medicine needs to accept the university rules, which are often rigid and difficult to understand to a practising physician $(27,28)$. But it is generally better to follow the rules of the other departments than try to bend them. Even if one is successful in achieving a different standard, this success is usually considered to be linked to the "second level « of academic quality.

Accepting academic standard also means that family medicine departments should contribute to the work of the university and accept commitment to excellence and be in constant contact with practising physicians. Tensions with professional organisations of family medicine may arise and are not infrequent, but cooperation between the univerity department and the professional organisation is of vital importance for the success of both parties. The next challenge is the burden posed on the medical teachers by the additional task of teaching and practising (29). If family doctors are self-employed, this problem is often very difficult.

Family medicine must also retain its specificities. All too frequently, the new departments of family medicine become too much like all the other departments in the attempt of being equal. When family medicine is considered as an academic discipline, this requires following the same strict standards of academic excellence, but this also requires from the family medicine academics to educate and research the difficult and sometimes poorly understood problems that are inherent to family medicine and not to follow the easy path of the well established disciplines that have already proven themselves. This decision is by no means easy, but it is the only logical if one wants to maintain family medicine as the dicipline equal to others (30).

\section{Conclusion}

Maintaining specificities and adaptiation to the challenges is the rule and the norm. This is not easy, but is essential if one wants to keep the academia alive and family medicine and academic medicine flourishing (2).

Conflict of interest: The author declare that he has no conflict of interest. This article was not sponsored by any external organisation.

\section{References}

1. Marušić A, editor. Revitalization of academic medicine. Zagreb: Medicinska naklada; 2005.

2. Clark J. For the International Campaign to Revitalise Academic Medicine. Five futures for academic medicine: the ICRAM scenarios. BMJ. 2005;331(7508):101-4.

3. Sewankambo N. Academic medicine and global health responsibilities. BMJ. 2004;329(7469):752-3.

4. McManus IC. How will medical education change? Lancet. 1991;337:1519-21.

5. Švab I. Changing research culture. Ann Fam Med. 2004;2(Suppl 2):S30-S4.

6. Švab I. Take home message from the president of Wonca Europe. PrimaryCare 2010;10(1):13.

7. Evans PR. Medicine in Europe: The changing scene in general practice in Europe. BMJ. 1994;308(6929):645-8.

8. Scherger JE. A medical student's perspective on preceptors in family practice. J Fam Pract. 1975;2(3):201-3.

9. Morris CG, Chen FM. Training residents in community health centers: facilitators and barriers. Ann Fam Med. 2009;7(6):488-94.

10. Gordon J. ABC of learning and teaching in medicine: One to one teaching and feedback. BMJ. 2003;326(7388):543-5.

11. Jaques D. ABC of learning and teaching in medicine: Teaching small groups. BMJ. 2003;326(7387):492-4. 
12. Walsh JM, Papadakis M. Prevention training and medical residency. Am J Prev Med. 1994;10:168-71.

13. Kochen MM, Himmel W. Academic careers in general practice:scientific requirements in Europe. Eur J Gen Pract. 2000;6(2):62-5.

14. Grover M. Teaching general rules during ambulatory education. Fam Med. 2003;35(3):160-2.

15. Heyrman J, ed. EURACT Educational agenda of general practice/family medicine. Leuven: EURACT; 2005.

16. Green LA. The research domain of family medicine. Ann Fam Med. 2004;2(Suppl 2):S23-S9.

17. Švab I. The medical speciality of family medicine:the European perspective. PrimaryCare. 2010;10(4):59-60.

18. Švab I, Bulc M. Academic medicine: What does an outsider have to offer? Croat Med J. 2004;45(3):254-5.

19. Švab I, Petek Šter M. Long-term evaluation of undergraduate family medicine curriculum in Slovenia. Srp Arh Celok Lek. 2008;136(5-6):274-9.

20. Dornan T, Bundy C. What can experience add to early medical education? Consensus survey. BMJ. 2004;329(7470):834-7.

21. Snellen-Balendong $H$. Rationale underlying the design of a problem-basedcurriculum. In: Bouhuijs PAJ, Schmidt HG, van Berkel HJM, editors. Problem-based learning as an educational strategy. Maastricht: Network publications; 1993. p. 69-78.

22. Švab I, Ribarič S, Plemenitaš A, Kopač I, Pirtošek Z. Sodobno medicinsko izobraževanje (Modern medical education). Zdrav Vestn. 2004;73(3):109-11.

23. Lowry S. Curriculum design. BMJ. 1992;305:140911.

24. Švab I. The challenged values of family medicine. In: Rumboldt M, Petric D, editors. Proceedings of the XVI kongres obiteljske medicine. Split: HUOM; 2009. p. 7-3.

25. UEMO consensus document on specific training for general practice. In: Kennedy TE, editor. UEMO reference book 2000/2001. UEMO. p. 30-5.

26. Criteria for general practitioner trainers. In: Kennedy TE, editor. UEMO reference book 2000/2001. UEMO. p. 22-3.

27. Abbasi K. Let's dump impact factors. BMJ. 2004;329(7471):0-h.

28. Gibson JC. Impact factor in general practice. Qual Prim Care. 2011;19(1):3-4.

29. Beasley JW, Hankey TH, Erickson R, Stange KC, Mundt M, Elliott M, et al. How many problems do family physicians manage at each encounter? A WReN study. Ann Fam Med. 2004;2(5):405-10.

30. Švab I. Academic family medicine - the jewel in the crown or the useless aristocrate? Rev Port Clin Geral. 2007;23:6-8. 